\title{
Commentary: The static use of the transannular patch in the repair of tetralogy of Fallot
}

George M. Alfieris, MD, Michael F. Swartz, PhD, and Mohamed Algahim, MD

\author{
From the Division of Cardiac Surgery, Department of Surgery, University of Rochester Medical Center, Roches- \\ ter, NY. \\ Disclosures: Authors have nothing to disclose with regard to commercial support. \\ Received for publication Sept 4, 2019; revisions received Sept 4, 2019; accepted for publication Sept 5, 2019; \\ available ahead of print Oct 18, 2019. \\ Address for reprints: George M. Alfieris, MD, Strong Memorial Hospital, Box Surg/Cardiac, 601 Elmwood Ave, \\ Rochester, NY 14642 (E-mail: George alfieris@urmc.rochester.edu). \\ J Thorac Cardiovasc Surg 2020;159:239-40 \\ $0022-5223 / \$ 36.00$ \\ Copyright (c) 2019 by The American Association for Thoracic Surgery \\ https://doi.org/10.1016/j.jtcvs.2019.09.036
}

\begin{abstract}
Although the Society of Thoracic Surgeons Congenital database has been instrumental in the understanding of hospital outcomes following the repair of tetralogy of Fallot (ToF), insights into the mid- and long-term results are less concrete. Currently, the mid- and long-term outcomes reported following ToF repair are often from single centers, or even single surgeons, which may not be largely applicable outside of the region, country, or even continent. ${ }^{1,2}$ Romeo and colleagues, ${ }^{3}$ in this issue of the Journal, have presented their results of a meta-analysis examining both the mortality and rate of reintervention following ToF repair.
\end{abstract}

As expected, and as evidenced by the report from the Society of Thoracic Surgeons database, ${ }^{4}$ palliative shunting and the use of a transventricular approach for the repair of ToF have both declined over the study period. In addition, the authors have provided evidence supporting the benefits for ToF repair during infancy. What is surprising, however, is both the relative consistency and outcomes following the use of a transannular patch (TAP). The use of a TAP was static over the study period and was necessary in nearly $50 \%$ of cases. Furthermore, patients requiring a TAP were at risk for both early and late mortality. ${ }^{3}$

The explanation for the static use of a TAP may be from the aggressive nature of many surgeons, who now prefer repair during infancy rather than a palliative shunt. Infants who several decades previously might have received a modified Blalock-Tausig shunt due to the limited size of the pulmonary annulus in the more current era might receive a complete repair with a TAP. Unfortunately, the current meta-analysis was unable to differentiate between the varying approaches used in the creation of a TAP. During the past several decades, several groups have favored the use of either a limited TAP, or the use of an infundibular sparring approach. ${ }^{5,6}$ These approaches, although classified as a TAP, prevent excessive pulmonary annular expansion and may limit the degree of pulmonary insufficiency. within this report.

\section{References} 220-36.e8.

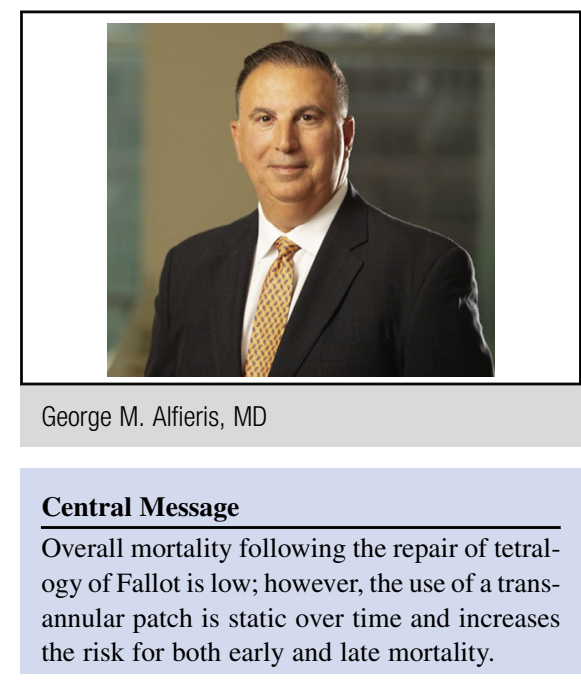

See Article page 220.

Since the use of a TAP has remained static over several decades, and its use results in an increased risk for early and late mortality, it may be necessary to construct several new and precise definitions rather than the current broad grouping of this traditional term. A description of the materials such as Dacron, homograft patch, polytetrafluoroethylene, or pericardium, as well the degree of annular expansion, are integral information that is currently missing from the current Society of Thoracic Surgeons Congenital Database form. A precise description of the types of TAPs that are constructed may lead to a greater understanding of which children, and which TAPs, contribute to both the early and late mortality observed

1. Singh NM, Loomba RS, Gudausky TM, Mitchell ME. Monoscusp valve placement in children with tetralogy of Fallot undergoing repair with transannular patch: a functioning pulmonary valve does not improve immediate postsurgical outcomes. Congenit Heart Dis. 2018;13:935-43.

2. Ho AB, Bharucha T, Jones E, Thuraisingham J, Kaarne M, Viola N. Primary surgical repair of tetralogy of Fallot at under three months of age. Asian Cardiovasc Thorac Ann. 2018;26:529-34.

3. Romeo JLR, Etnel JRG, Takkenberg JJM, Roos-Hesselink JW, Helbing WA, van de Woestijne P, et al. Outcome after surgical repair of tetralogy of Fallot: a systematic review and meta-analysis. J Thorac Cardiovasc Surg. 2020;159:

4. Jacobs JP, Mayer JE, Pasquali SK, Hill KD, Overman DM, St Louis JD, et al. The Society of Thoracic surgeons Congenital Heart Surgery database: 2018 update on outcomes and quality. Ann Thorac Surg. 2018;105:680-9. 
5. Simon BV, Swartz MF, Egan M, Cholette JM, Gensini F, Aflieris GM. Use of a Dacron annular sparing versus limited transannular patch with nominal pulmonary annular expansion in infants with tetralogy of Fallot. Ann Thorac Surg. 2017;103:186-92.
6. Niu MC, Morris SA, Morales DL, Fraser CD, Kim JJ. Low incidence of arrhythmias in the right ventricular infundibulum sparing approach to tetralogy of Fallot repair. Pediatr Cardiol. 2014;35:261-9. 